* Mestrando pelo programa de Mestrado em Direito Negocial da UEL; Bolsista CAPES; Pós-Graduado em Direito Empresarial pela PUC-PR e em Direito Civil e Processo pela UNAR. Email: philippe_mont@ hotmail.com

** Doutora em Direito do Estado pela Pontifícia Universidade Católica de São Paulo e Mestre em Direito do Estado pela Pontifícia Universidade Católica de São Paulo. Professora do Programa de Mestrado em Direito Negocial e do Curso de Graduação e Pós Graduação em Direito da Universidade Estadual de Londrina. Professora ColaboradoraConvidada do Curso de Pós Graduação em Direito Civil Contemporâneo do Instituto Brasileiro de Estudos e Pesquisas Sócio-Econômicas. E-mail: mkempferb@ gmail.com

\section{A informalidade e a inclusão econômica por meio do Estatuto Nacional da Microempresa}

\author{
INFORMALITY AND ECONOMIC INCLUSION \\ THROUgh National Statute of \\ MICROENTERPRISE
}
* Philippe Antonio Azedo Monteiro ** Marlene Kempfer

Resumo: O presente estudo se propõe a analisar e concluir se o atual Estatuto Nacional da Microempresa e da Empresa de Pequeno Porte (LC 123/06) tem efetivo potencial de promover o direito a inclusão econômica no Brasil. Os fundamentos teóricos da pesquisa têm por referência a obra $\mathrm{O}$ Mistério do Capital (2001) de Hernando de Soto, que apresenta análise e aponta caminhos diante da constatação de que o capitalismo não promoveu inclusões, tal qual a econômica, em países não desenvolvidos, dentre os quais pode-se incluir o Brasil. Dados confirmam que a informalidade é uma realidade que deve preocupar os governos, face as externalidades negativas inerentes a este ambiente econômico e social. Hernando de Soto aponta a necessidade de decisões jurídicas e políticas de inclusão ao mercado do que denomina de capital morto; ou seja, potencialidades que tendo acesso aos mecanismos jurídicos que lhes garanta o direito de propriedade, galgam a condição de capital formal e podem contribuir para a dinâmica positiva do capitalismo. A pesquisa busca na Constituição Federal de 1988 a competência do Estado (Art. $174 \mathrm{CF} / 88$ ) para, por meio da intervenção normativa (Legislativo), fiscalização (Executivo) e incentivo (Legislativo e Executivo), promover oportunidades e reduzir a informalidade. Tal iniciativa estatal objetiva o acesso e a permanência no mercado, além de contribuir para a efetividade do Regime Jurídico Econômico Constitucional (Art. $170 \mathrm{CF} /$ 88) e para os objetivos de desenvolvimento nacional (Art. $3^{\circ}$ $\mathrm{CF} / 88$ ). A Lei Complementar 123/06, com suas alterações, introduziu normas gerais nos termos do Art. 179 da $\mathrm{CF} / 88$, portanto, um regime uniforme de natureza federativa, que prescreve direito a um regime jurídico diferenciado para obrigações tributárias, administrativas, previdenciárias e creditícias aos microempreendedores.

Palavras-chave: Inclusão econômica. Informalidade. Intervenção estatal. 


\begin{abstract}
This study aims to analyze and conclude whether the current National Statute of Micro and Small Businesses (LC 123/06) effectively has the potential to promote the right economic inclusion in Brazil. The theoretical foundations of research have by reference the work The Capital of Mystery (2001) of Hernando de Soto, which features analysis and points out ways given the fact that capitalism did not promote inclusions, like the economy, in undeveloped countries, among which can include Brazil. Data confirm that informality is a reality that should concern governments face the negative externalities inherent in this economic and social environment. Hernando de Soto points out the need for legal decisions and inclusion policies at the market what he calls dead capital; potential that having access to legal mechanisms which guarantees them the right to property, seek the formal capital condition and can contribute to the positive dynamics of capitalism. The research aims in the Federal Constitution of 1988 the jurisdiction of the State (Art. 174 FC/88) for, through regulatory intervention (Legislative), supervision (Executive) and incentives (legislative and executive), promote opportunities and reduce informality. Such state initiative aims to access and stay in the market, and contribute to the effectiveness of the Economic Constitutional Legal Framework (Art. 170 FC/88) and national development goals (Art. 3 FC/88). Complementary Law 123/06, as amended, introduced general rules under Art. 179 of $\mathrm{FC} / 88$, so a uniform system of federal nature, which prescribes the right to a different legal regime for tax, administrative, social security and lending to microentrepreneurs.
\end{abstract}

Keywords: Economic inclusion. Informality. State intervention. 


\section{INTRODUÇÃO}

O tema da inclusão econômica e do combate à informalidade tem, desde o final do século passado, conquistado expressivo destaque na literatura especializada e no discurso político, mormente no Brasil, que possui um significativo mercado periférico.

O Brasil é um país de severos contrastes, enquanto de um lado se observa o agronegócio e as grandes indústrias em expansão, de outro, o desenvolvimento divide espaço com um forte mercado informal que atua, especialmente, nos setores do comércio e serviços.

Hernando de Soto, na obra O Mistério do Capital (SOTO, 2001), estuda a informalidade e a necessidade de inclusão econômica em países não desenvolvidos e ex-comunistas de modo que mais pessoas possam usufruir das externalidades positivas do capitalismo. Destaca a importância de ações jurídicas e políticas de inclusão desse potencial que denomina de capital morto.

A presente pesquisa toma por fundamento tais estudos e se propõe a analisar e concluir se o atual Estatuto Nacional da Microempresa e da Empresa de Pequeno Porte (BRASIL, 2006), por meio das oportunidades que proporciona, poderá promover o direito a inclusão econômica e a redução da informalidade no Brasil.

Os desafios são muitos, pois, além de atrair para a formalidade é preciso investir em políticas para a permanência no mercado. Por isso, defende-se políticas estatais de fomento ao empreendedorismo nos pequenos negócios, pois além de gerar oportunidades de trabalho, estimulam a concorrência e a inovação. Enfim, os investimentos direcionados às microempresas revertem-se diretamente na promoção dos objetivos constitucionais de erradicar a pobreza, a marginalização, reduzir as desigualdades sociais e estimular o desenvolvimento no país.

A pesquisa recorre a fontes bibliográficas, normativas e dados estatísticos, para destacar o tratamento diferenciado às microempresas e empresas de pequeno porte na concretização do direito a inclusão econômica no Brasil.

\section{O MISTÉRIO DO CAPITAL: ENERGIA POTENCIAL DOS ATIVOS E A REDOMA DE VIDRO DE BRAUDEL}

A obra O Mistério do Capital (SOTO, 2001) de Hernando de Soto, afigurase como estímulo condutor da presente pesquisa. O livro é resultado de um 
estudo de campo realizado pelo autor e sua equipe, sobre o modo de vida dos povos da Ásia, Oriente Médio, América Latina e Caribe. O autor erigiu como objeto de investigação os países subcapitalizados, pois a obra se propõe a demonstrar que os povos do terceiro mundo e das antigas nações comunistas não conseguem viver o capitalismo tal qual o ocidente (Europa, Norte América e outros), já que os contratos sociais informais impedem a transformação de ativos em capital.

A informalidade e a irregularidade documental, típicas das regiões pesquisadas, fazem com que o ativo, que poderia tornar-se capital e ser utilizado para a geração de crédito, seja, na realidade, um capital morto, pois a falta de lastro e de regularidade impedem a sua utilização.

Entre as importantes afirmações que Hernando de Soto (2001) registra em sua obra, são destacados para este estudo, apenas dois pontos: a energia potencial dos ativos e a redoma de vidro de Braudel. Ambos estão localizados no capítulo terceiro da obra O Mistério do Capital.

O tópico sobre a energia potencial dos ativos aborda a capacidade de um ativo - uma casa, uma quota social, uma máquina - em ser usado para produzir, assegurar ou garantir valores no mercado econômico (SOTO, 2001, p. 57). Dentro de um sistema formal, como o dos países desenvolvidos, o ativo é facilmente transformado em capital, aproveitando o potencial econômico nele existente. Entretanto, esse potencial não pode ser explorado caso o ativo padeça de irregularidade documental, pois, sem lastro, torna-se um capital morto, tal qual ocorre em meio à informalidade dos países subcapitalizados.

O sistema formal de propriedade permite a transformação de um ativo em capital, pois o capital nasce da representação escrita das qualidades econômicas de um ativo - escritura, fiança, contrato e outros registros - e não do aspecto físico da coisa. Trata-se de uma visão conceitual e não material. Uma escritura, por exemplo, representa qualidades invisíveis, com potencial de produzir valor e qualidades que são economicamente utilizáveis.

A irregularidade documental resulta em, cada vez mais, informalidade, pois, uma casa, que poderia ser usada como garantia na tomada de um crédito junto ao banco, de nada irá servir se não estiver escriturada em favor do interessado. Aliás, as principais dificuldades enfrentadas na obtenção de crédito por microempreendedores residem justamente na falta de garantias, coadunando ao que Soto $(2001$, p. 60 ) discorreu sobre a energia potencial dos ativos e a dificuldade na transformação do ativo em capital. Diante disso, expõe a criação de mecanismos de facilitação ao crédito em bancos públicos e também fundos 
de garantia para lastrear as transações feitas por microempresários e, assim, suprir essa lacuna.

Os tópicos estão intimamente conectados, pois, na redoma de vidro de Braudel, Soto (2001, p. 82-84) referindo-se ao historiador Fernand Braudel, expõe que a formação de capital foi alcançada por poucos privilegiados, uma minoria com acesso a oportunidades econômicas, ou seja, uma parcela social que parece estar em uma espécie de redoma de vidro que a separa do restante da sociedade. Aponta que, nos países subdesenvolvidos, a maioria da população não consegue ter os frutos do seu trabalho representados no sistema formal, ficam do lado de fora dessa redoma. Enquanto que, dentro da redoma, encontrase uma minoria, daqueles capazes de acessar as oportunidades legais e pagando a advogados para auxiliá-los a superar as burocracias do sistema.

Soto (2001, p. 51) destaca a importância da representatividade dos ativos dos cidadãos, pois, o que cria o capital e possibilita avanços sociais, econômicos e culturais, não são os bens físicos em si, mas o modo com que são utilizados. A maneira como os direitos à propriedade dos bens são definidos é fundamental para o progresso. As dificuldades que o Terceiro Mundo encontra hoje para integrar setores extralegais à formalidade, são similares ao que viveu o Ocidente no século XIX. É crucial para se construir esta ponte que os governos compreendam que as leis precisam alcançar a realidade do povo.

Esse estudo aponta a intervenção do Estado por meio normativo, incentivo, fiscalização e planejamento (Art. 174) (BRASIL, 1988), para diminuir e até superar a falta de regularidades formais de registros, acesso ao crédito e oportunidades de negócios. Destaca-se a necessidade de atrair as potencialidades que estão no âmbito do capital morto para que sejam estimuladas a ter acesso e permanecer na redoma de vidro de Braudel.

\section{A INTERVENÇÃO DO ESTADO POR MEIO NORMATIVO E DE INCENTIVO PARA PROMOVER A INCLUSÃO ECONÔ- MICA}

A título de contextualização histórica, destaca-se que o debate sobre a importância da microempresa para o desenvolvimento econômico brasileiro toma corpo no início da década de 1980 (RIBEIRO, 1984, p. 14). Nessa época, começaram a surgir ações efetivas na seara legislativa. As medidas se iniciam em 1980, com o Decreto-Lei n ${ }^{\circ} 1.780$ (norma federal), que concedeu isenção de imposto sobre a renda de pequenas empresas e dispensou o cumprimento de 
obrigações acessórias (BRASIL, 1980). No ano seguinte, 1981, a Lei nº . 6.939, estabeleceu um regime sumário de registro e arquivamento no Registro do Comércio, facilitando os atos registrais (BRASIL, 1981).

Em 1984 foi aprovada a Lei ${ }^{\circ}$. 7.256, que disciplinou pela primeira vez a categoria de pequena empresa e, em linhas gerais, estabeleceu um tratamento privilegiado a microempresa nos campos administrativo, tributário, previdenciário, trabalhista e comercial. A lei ansiava facilitar a constituição e o funcionamento das unidades produtivas de pequenas proporções e, ainda, fortalecer a participação no processo de desenvolvimento econômico e social do país (BRASIL, 1984a).

Ainda em 1984 a Lei Complementar $n^{\circ} .48$ (BRASIL, 1984b) isentou as microempresas do recolhimento de ICM (imposto sobre circulação de mercadoria) e ISS (imposto sobre serviço), isenção essa ampliada pouco depois pela lei 7.519, de julho de 1986.

Embora tais leis já tivessem por escopo o tratamento diferenciado às microempresas, este intento alcançou verdadeiro avanço com a promulgação da Constituição de 1988. O Estado brasileiro assumiu a competência para, por meio dos governos, promover inclusão econômica e inseriu esta atribuição em nível constitucional, no capítulo que trata dos pilares que devem ser considerados no âmbito das relações econômicas. Assim, por ser política de estado é vinculatória para todos os governos.

Após a aprovação da Constituição de 1988, o comando do Art. 170, inc. IX, fez com que outras medidas importantes fossem concretizadas, entre elas, foram aprovadas as Leis $n^{\circ} .8 .029$ e 8.154 de 1990 e o Decreto $n^{\circ} .99 .570$ de 1990, criando o SEBRAE (Serviço Brasileiro de Apoio à Micro e Pequenas Empresas), um órgão técnico de apoio ao desenvolvimento da atividade empresarial de pequeno porte, voltada para a difusão de programas e projetos de promoção e fortalecimento das micro e pequenas empresas.

Em 1994, a Lei n ${ }^{\circ}$. 8.864, passou a regular o Estatuto da Pequena Empresa, reiterando, em grande medida, benefícios já assegurados anteriormente. Embora a Lei não tivesse causado grande impacto pela falta de regulamentação, elevou a receita bruta anual de enquadramento da microempresa, ampliando o leque de abrangência, além de fazer surgir, pela primeira vez, a figura da empresa de pequeno porte, conforme previsto na Constituição Federal.

Em 1996, a Medida Provisória ${ }^{\circ}$. 1.526, dispôs sobre benefícios do regime tributário diferenciado. E, ainda em 1996, adveio a Lei $n^{\circ} .9 .317$, criando o regime tributário conhecido como SIMPLES (sistema integrado de pagamento 
de impostos e contribuições das microempresas e empresas de pequeno porte). As empresas que aderissem a esse regime simplificado teriam o benefício de pagar diversos tributos mediante um único recolhimento mensal proporcional ao seu faturamento.

No ano de 1999, foi sancionada a Lei $n^{\circ}$. 9.841, que recebeu a denominação de "Estatuto da Pequena Empresa e da Empresa de Pequeno Porte". Não obstante tal fim, essa lei teve como objetivo facilitar a constituição e o funcionamento das microempresas, de forma a assegurar o fortalecimento de sua participação no processo de desenvolvimento econômico e social. O Estatuto passou a prever tratamento favorecido às Microempresas e Empresas de Pequeno Porte em campos não abrangidos pela lei do Simples; isto significa que, enquanto o Estatuto objetivou facilitar a constituição e o funcionamento da microempresa, assegurando o fortalecimento de sua participação no processo de desenvolvimento econômico e social; o SIMPLES estabeleceu tratamento diferenciado nos campos dos impostos e contribuições.

O grande marco regulatório no campo da microempresa data de 2006, com a publicação da Lei Complementar 123, reconhecida por "Lei Geral da Micro e Pequena Empresa”. Esta lei, contém normas gerais e federais e, em cumprimento à previsão constitucional, prevê um regime diferenciado tributário de arrecadação de impostos e contribuições, simplificações de deveres nos âmbitos administrativo (licenças, registros, baixas) e trabalhista, estímulo para acesso ao crédito público e de participação nos negócios públicos, sistema de fiscalização primeiramente de orientação e um importante sistema de gestão federativo com órgãos colegiados envolvendo a participação dos membros da federação e da sociedade.

O constituinte, por meio do Art. 179 da $\mathrm{CF} / 88$, incumbiu ao legislador e aos governantes, por meio de leis e políticas públicas, dispensarem tratamento jurídico diferenciado às microempresas e empresas de pequeno porte em obrigações administrativas, tributárias, previdenciárias e creditícias:

A União, os Estados, o Distrito Federal e os Municípios dispensarão às microempresas e às empresas de pequeno porte, assim definidas em lei, tratamento jurídico diferenciado, visando a incentivá-las pela simplificação de suas obrigações administrativas, tributárias, previdenciárias e creditícias, ou pela eliminação ou redução destas por meio de lei. (BRASIL, 1988). 
Sobre o tratamento favorecido, esclareceu Martins (1992, p. 79), que:

Tratamento favorecido é tratamento mais benéfico, com menos encargos, ônus e obrigações, com mais apoio, auxílio e suporte das autoridades [...] o discurso constituinte explicita que tal tratamento diferenciado será resultante de duas formas de incentivos, a saber: a) simplificação das obrigações administrativas, tributárias, previdenciárias e creditícias; b) eliminação ou redução de tais obrigações.

O tratamento especial dispensado às micro e pequenas empresas é corolário do princípio da igualdade material no âmbito econômico para que, com o acesso se promova o direito à livre iniciativa e, com a permanência, a livre concorrência:

O desafio é ajudá-los a alcançar gradualmente a competitividade genuína, aperfeiçoando as suas qualificações e o acesso à tecnologia, ao crédito e ao mercado. Para tanto, é necessário ultrapassar o âmbito de políticas meramente setoriais; é preciso contemplar as formas de integração do universo dos pequenos produtores e empreendedores na economia nacional. (SACHS, 2003, p. 58).

Neste sentido é fundamental a intervenção estatal, uma vez que para sair da informalidade e competir com os desafios do mercado atual é dever dos governos promoverem investimentos públicos por meio das diferentes formas de fomentos.

\section{A LEI COMPLEMENTAR 123/06 E AS OPORTUNIDADES PARAAINCLUSÃO ECONÔMICA}

O professor Antônio Lopes de Sá, na obra Tudo Sobre a Microempresa (SÁ, 1985, p. 9), se intitulou o primeiro autor brasileiro a escrever sobre a tema. Em sua época, já se apontava que para merecer a classificação e os benefícios legais dispensados às microempresas deveria ser considerada a receita ou volume de vendas. Este critério de enquadramento continua sendo usado até hoje.

Aponta Montaño, que as micro e pequenas empresas se caracterizam por:

[...] poucos trabalhadores, baixo volume de produção e comercialização e reduzido mercado e raio de incidência; pouco complexa - altamente centralizada, com pouca estratificação e escassa divisão de tarefas e 
papéis; e relativamente informal - insuficiente definição explícita de objetivos, normas, sistemas de sanções e recompensas, assim como irregular aplicação das leis Sociais e Empresariais (MONTAÑO, 1999, p. 15).

No Brasil, a LC 123/06, atualizada pela LC 147/14, classifica seus destinatários em três categorias, segundo critérios de faturamento ${ }^{1}$ e atuação: Microempreendedor Individual (MEI), até R \$ 60.000,00; Microempresa (ME) até R \$ 360.000,00; e Empresa de Pequeno Porte (EPP) acima de R \$360.000,00 e igual ou inferior a $\mathrm{R} \$ 3.600 .000,00 \mathrm{e}$, ainda, poderá chegar a $\mathrm{R} \$ 7.200 .000,00$, com o estímulo à exportação².

A possibilidade de enquadramento como micro e pequena empresa não mais se restringe às sociedades empresárias, de sorte que todos os benefícios podem ser, também, alcançados pelo Microempreendedor Individual (MEI) e a Empresa Individual de Responsabilidade Limitada (EIRELI), nos termos da LC 128/2008 e da Lei 12.441/2011, respectivamente.

A LC 147/14, alterou a Lei Geral da Micro e Pequena Empresa (LC 123/06), ampliando as atividades que podem aderir ao sistema do Simples Nacional. Foram incluídas mais de 142 atividades, entre eles, setores de produção intelectual, técnica e científica, tais como advogados, médicos, dentistas, psicólogos, engenheiros.

\subsection{Política de Estímulo ao Crédito, Garantia e Inovações}

Conforme alertou Hernando de Soto em sua obra (SOTO, 2001, p. 51), a dificuldade de acesso ao crédito é um óbice ao desenvolvimento do capital que denomina de "capital morto", pois as instituições financeiras tendem a inibir a liberação de crédito por falta de garantias reais a lastrear os empréstimos.

\footnotetext{
${ }^{1}$ A LC 123/06 adotou como parâmetro classificatório de faturamento a receita bruta anual e, para não pairar dúvidas, esclareceu, no Art. $3^{\circ}$, inc. II, $\S 1^{\circ}$, que: "Considera-se receita bruta, para fins do disposto no caput deste Art., o produto da venda de bens e serviços nas operações de conta própria, o preço dos serviços prestados e o resultado nas operações em conta alheia, não incluídas as vendas canceladas e os descontos incondicionais concedidos" (BRASIL, 2006).

2 Sobre os citados valores, destaca-se o Projeto de Lei Complementar 25/07, aprovado na Câmara dos Deputados e que segue ao Senado. O plenário votou pelo aumenta do limite de enquadramento da microempresa no regime especial de tributação unificada. Pela proposta, a receita bruta anual máxima permitida para a microempresa passará de R\$ 360 mil para R\$ $900 \mathrm{mil}$. No caso das empresas de pequeno porte, será permitido para o intervalo de R\$ 900 mil a $R \$ 14,4$ milhões anuais. Atualmente, é de R\$360 mil a R\$ 3,6 milhões. Para as empresas de pequeno porte, em 2017, o novo limite iria até R\$7,2 milhões. E, somente em 2018 se admitiria empresas com receita bruta de até R\$ 14,4 milhões.
} 
Com objetivo de enfrentar essa realidade a LC 123/06, em seu Art. 58, impõe aos bancos públicos o dever de manutenção de linhas de crédito específicas para as MEI, ME e EPP. Estabelece importantes mecanismos de controle desta obrigação: obrigar que tais créditos sejam identificadas nos orçamentos dos bancos e que desta obrigação seja dada ampla divulgação; apresentar relatório que mostre a alocação dos recursos de crédito, identificando os que foram utilizados e a explicação do bom ou mau desempenho da política pública; estes dados farão parte do Sistema de Informações de Crédito - SCR, do Banco Central do Brasil, para que possa estimular a oferta de créditos por bancos privados.

Nessa toada, por exemplo, foi lançado pelo governo federal, em 08/2011, o Programa Nacional de Microcrédito Produtivo Orientado (Programa Crescer), com o objetivo de facilitar as condições de financiamento, com menores taxas de juros e metas de empréstimos a serem atingidas pelos bancos públicos, oferecendo crédito de até $\mathrm{R} \$ 15$ mil, com juros menores (próximos a $5 \%$ ao ano).

O Portal da Transparência aponta que o valor investido em operações de microcrédito teve um crescimento até 2012, seguido de uma queda em 2013 e 2014.

Gráfico 1 - Valor investido em operações de microcrédito para Microempresas

RS 300.000.000,00

$\mathrm{R} \$ 279.768 .852,60$

$R \$ 250.000 .000,00$

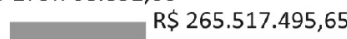

$\mathrm{R} \$ 200.000 .000,00$

$\mathrm{R} \$ 150.000 .000,00$

RS $100.000 .000,00$

$\mathrm{R} \$ 72.813 .837,13$

$\mathrm{R} \$ 50.000 .000,00$

$R \$ 0,00$

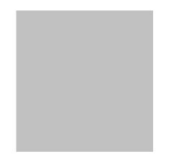

$\mathrm{R} \$ 178.357 .698,09$

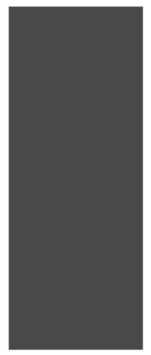

-2011 $2012 \square 2013 \square 2014$ 
Há mecanismos oficiais de prestação de garantias, com a criação de fundos de aval para facilitar a obtenção de crédito por micro e pequenas empresas (Art. 60-A). Ao tomar crédito, empreendedores de menor porte encontram dificuldades em atender as garantias exigidas pelas instituições financeiras, que inviabilizam a contratação do financiamento desejado, ou levam à aprovação em condições menos favoráveis. Isto, se deve pela falta de ativos capazes de lastrear as transações. Assim, ao complementar as garantias oferecidas pelas empresas aumentam as chances de aprovação dos pedidos de crédito. Este poderá ser utilizado para aquisição de equipamentos, expansão de unidades produtivas, aquisição de softwares, capital de giro, entre outros. Gerar oportunidade por meio deste sistema garantidor de crédito é fundamental para a redução das barreiras enfrentadas pelos pequenos empresários que necessitam de crédito.

Em relação ao apoio às inovações com o advento da LC 123/06 tem-se políticas de âmbito nacional. Define a lei que inovar é a concepção de um novo produto ou processo de fabricação, agregação de novas funcionalidades ou características ao produto ou processo produtivo.

Para implementar políticas de incentivo nestas iniciativas o micro ou pequeno empreendedor terá agências de fomento ${ }^{3}, \mathrm{ICT}^{4}$, núcleos de inovação tecnológica ${ }^{5}$ e as instituições de apoio ${ }^{6}$, inclusive quando estas revestirem a forma de incubadoras.

Sobre as tais incubadoras, Renaldo Limiro da Silva (2007, p. 195), aponta que:

Uma incubadora de empresas é um mecanismo que estimula a criação e o desenvolvimento de micro e pequenas empresas (industriais, de prestação de serviços, de base tecnológica ou de manufaturas leves), oferecendo suporte técnico, gerencial e formação complementar do empreendedor. A incubadora também facilita e agiliza o processo de inovação tecnológica nas micro e pequenas empresas. Em geral, as incubadoras dispõem de um espaço físico especialmente construído ou adaptado para alojar temporariamente micro e pequenas empresas e oferece uma série de

\footnotetext{
3 Agências de fomento: Instituição pública ou privada que atue no financiamento de ações e promoção da ciência, da tecnologia e da inovação.

${ }^{4}$ Instituição Científica e Tecnológica (ICT): entidade da administração pública que execute atividades de pesquisa básica ou aplicada de caráter científico ou tecnológico;

5 Núcleo de inovação tecnológica: núcleo ou órgão constituído por uma ou mais ICT com a finalidade de gerir sua política de inovação.

${ }^{6}$ Instituição com a finalidade apoiar a projetos de pesquisa, ensino e extensão e de desenvolvimento.
} 
serviços, como cursos de capacitação gerencial, assessorias, consultorias, orientação na elaboração de projetos a instituições de fomento, serviços administrativos, acesso a informações etc.

O estímulo à inovação previsto na LC 123/06 se reveste em favorecimento e simplificação do acesso a tecnologias. As instituições referidas devem publicar relatório circunstanciado com as estratégias para maximização da participação das pequenas e microempresas e os recursos alocados a esse fim. A lei estipula, ainda, meta de, no mínimo, 20\% dos recursos destinados à inovação sejam destinados para a micro e pequenas empresas.

Há, ainda, uma previsão de isenção de impostos e contribuições incidentes na aquisição ou importação de equipamentos e máquinas diretamente por micro e pequenas empresas para incorporação ao seu ativo imobilizado. Podem ser reduzidas a zero as alíquotas de IPI, Cofins, PIS/Pasep, Cofins-Importação, PIS/Pasep-Importação e ICMS.

\subsection{Simplificação De Obrigações Administrativas, Trabalhistas E Tributárias E Fiscalização Orientativa}

A Lei Complementar 123/06 prevê a desburocratização e o acesso ao mercado com facilitação da constituição das empresas, a racionalização da exigência de documentos e de comprovantes para os MEI, ME e EPP.

A nosso ver, a burocracia pode ser um dos grandes obstáculos, o maior talvez, que poderão surgir para dificultar a efetiva implementação do Simples Nacional nos níveis da União, dos Estados/Distrito Federal e dos municípios. É que, por exemplo, quando da abertura ou do fechamento de qualquer microempresa ou empresa de pequeno porte, necessariamente esta tem que se reportar aos órgãos ou às entidades envolvidos nos três âmbitos de governo. Estes, por seu turno, têm a obrigação legal de unificar os respectivos procedimentos para tais fins, até mesmo por se constituir tal medida não somente uma inovação, mas também para alcançar a rapidez e a simplicidade buscadas pela Lei Complementar 123/06. (SILVA, 2007, p.42)

Uma das grandes dificuldades enfrentadas na constituição jurídica do empreendimento residia na falta de unicidade dos atos dos três âmbitos de governo. O legislador, então, conforme Art. $6^{\circ}$ da LC 123/06, dispôs que diante dos requisitos legais de segurança sanitária, metrologia, controle ambiental e 
prevenção contra incêndios deverão ser simplificados e as respectivas licenças com emissão unificada.

Outro avanço, para aquelas atividades que não ofereçam risco tais quais ao consumidor, ao ambiente, poderão iniciar as atividades sem licenças prévias. Terão que obter tais licenças posteriormente. Nesses casos, o Município-sede emitirá autorização, possibilitando, assim, o início das atividades logo após o ato do registro.

Na seara das relações trabalhistas, a LC 123/06, não foi muito além do que já disciplinava a Lei 9.841/99. Esta lei apontava que a pequena e a microempresa estavam dispensadas do cumprimento de determinadas obrigações acessórias que foram transcritas na LC 123/200: fixação de Quadro de Trabalho em suas dependências; anotação das férias dos empregados nos respectivos livros ou fichas de registro; e empregar e matricular seus aprendizes nos cursos dos Serviços Nacionais de Aprendizagem.

Em relação à simplificação das obrigações tributárias muitos avanços ocorreram. A realidade denunciava que o contribuinte estava sujeito a diferentes incidências tributárias (federal, estadual e municipal) e cada uma delas com seus meios de controle. A simplificação do sistema de arrecadação, é crucial ao funcionamento de toda a cadeia de favorecimento do microempreendedor.

Com a aprovação da lei, buscou-se instituir um regime especial unificado que contemplasse a maioria das microempresas e empresas de pequeno porte, nos seus diferentes segmentos de atuação no mercado, sejam atuantes no comércio, na indústria e também em alguns setores da prestação de serviços. (ALMEIDA, 2009, p. 36).

O regime especial unificado de arrecadação de tributos e contribuições criado para os MEI, ME e EPP é um importante instrumento criado pela LC 123/06:

De fato, reduzir a quantidade de guias que deverão ser calculadas e recolhidas é uma interessante forma de simplificação, dado a enorme quantidade de tributos que as empresas normais brasileiras têm o dever de calcular e recolher (ALMEIDA, 2009, p.37)

Este novo sistema considera por base de cálculo a receita bruta anual da empresa e as alíquotas variam conforme o nível das diferentes receitas. Quanto maior a receita bruta anual, maior a alíquota. Portanto, realiza-se o princípio da 
capacidade contributiva preconizado no Art. $145, \S 1^{\circ}$, da CF/88. Os anexos da Lei Complementar trazem tabelas organizadas de acordo com a atividade desenvolvida pela empresa em: comércio; indústria; locação de bens móveis e prestação de serviços.

$\mathrm{O}$ regime especial envolve o recolhimento dos seguintes impostos e contribuições federais: Imposto sobre a Renda da Pessoa Jurídica (IRPJ); Contribuição Social sobre o Lucro Líquido (CSLL); Imposto sobre Produtos Industrializados (IPI); Contribuição para o Financiamento da Seguridade Social (COFINS); Programa de Integração Social (PIS); Contribuição para a Seguridade Social (INSS). Em nível estadual o Imposto sobre Operações Relativas à Circulação de Mercadorias (ICM). E para os Municípios o Imposto sobre Serviços de Qualquer Natureza (ISS).

Criou-se um sistema federativo cuja arrecadação está centralizada junto a Secretaria da Receita Federal do Brasil. Os créditos advindos dos pagamentos efetuados pelos contribuintes serão depositados no Banco do Brasil, em favor de cada um dos credores-destinatários federativos. É o sistema de distribuição da arrecadação federal. A normatização deste sistema é de competência do Comitê Gestor do Simples Nacional (CGSN).

A LC 123/06 (Art. 55) traz, ainda, um sistema especial de fiscalização, que pode ser denominado de fiscalização com prioridade de orientação. Para tanto exige que antes de autuar seja realizada a dupla visita. Essa situação já foi apreciada pelo Judiciário e o caso resultou, inclusive, em invalidade formal da autuação por inobservar o critério da dupla visitação.

ADMINISTRATIVO. MICROEMPRESA. AUTOS DE INFRAÇÃO. DESCONSTITUIÇÃO. INOBSERVÂNCIA DO CRITÉRIO DADUPLA VISITAÇÃO. ART. 55 DA LC 123/06. ENQUADRAMENTO DA INFRAÇÃO NA PORTARIA INMETRO 436/2007. NORMA QUE NÃO SE REVESTE DO CONCEITO DE LEGISLAÇÃO INFRACONSTITUCIONAL.1. As infrações praticadas pelos microempresários, de acordo com o Art. 55 da LC 123/06, tem como regra, para autuação, a dupla visita $\left(\S 1^{\circ}\right)$, dispensando-se esse critério quando definida como infração fora da zona de alto risco $\left(\S 3^{\circ}\right) 2$. A Portaria 436/ 2007 foi editada pelo INMETRO para estabelecer quais as atividades de alto risco, complementando a exigência da LC 123/06 3. O Tribunal de Apelação considerou estar as infrações cometidas fora da zona de alto risco, situação que, pela lei complementar, não dispensa a dupla visita. 4 . Enquadramento legal das infrações na Portaria 436/2007 (arts. $1^{\circ}, 3^{\circ}$ e $4^{\circ}$ ), 
cuja violação não autoriza a abertura da via especial, por ser considerada legislação infraconstitucional. 5. Recurso especial não conhecido. (BRASIL, 2013).

Com este novo regime de atuação, cria-se um ambiente de aproximação entre administrados e o poder de polícia. Desta forma, espera-se diminuir a aplicação de sanções e estimular que as empresas atuem em conformidade com o a lei e seus regulamentos.

\subsection{Oportunidade Para Participar Dos Negócios Públicos}

Mais uma das formas do Estado e dos governos fomentarem a participação e o crescimento das microempresas é oferecer oportunidade de negócios em suas próprias compras e serviços. Este caminho abre possibilidades para permanência do micro e pequeno empresário no mercado.

Para participar dos negócios públicos é preciso realizar o certame licitatório. A Lei Complementar em análise, traz modificações em relação ao regime hoje disciplinado por meio da Lei 8.666/93. Prevê direitos especiais, que podem ser exercidos nas fases de habilitação e de classificação do participante MEI, ME e EPP. Destaca-se: o direito de apresentar a documentação de regularidade fiscal somente na assinatura do contrato com a administração pública (Art. 43); e, constatado empate (assim considera a proposta de até $10 \%$ acima do valor declarado vencedor e, na modalidade Pregão, o percentual de até 5\%), terá direito ao contrato (Art. 44). A respeito destas regras, Santos (2007, p. 31), esclarece:

Caso restem classificadas em primeiro lugar mais de uma proposta (propostas de idêntico valor, caracterizando situação de empate na acepção jurídica do termo), e uma delas for microempresa ou empresa de pequeno porte, esta terá preferência na contratação o desempate se dará pelo tratamento favorecido à microempresa ou empresa de pequeno porte. Este tratamento favorecido condiciona, entretanto, a preferência na contratação à oferta de proposta de preço inferior àquele orginalmente proposto. Como a lei não estabelece qualquer parâmetro para esta nova proposta, qualquer valor menor do que a proposta original deve ser reputado suficiente para que o desempate se efetive (proposta apenas RS 1 menor do que a original, por exemplo). Pode-se sustentar que, no caso de empate decorrente da apresentação de propostas idênticas por microempresa ou empresa de pequeno porte e outra licitante que não 
detenha esta condição, se deveria automaticamente dar preferência àquela, sem necessidade de apresentação de nova proposta, de menor valor.

Destaque-se a possibilidade, nos termos do Art. $48, \S 3^{\circ}$, de "estabelecer a prioridade de contratação para as microempresas e empresas de pequeno porte sediadas local ou regionalmente, até o limite de $10 \%$ (dez por cento) do melhor preço válido". (BRASIL, 2006). É o caminho para incentivar as atividades econômicas no mesmo âmbito territorial do consumo. Viabiliza-se geração de renda, emprego e desenvolvimento para a microrregião.

Enquanto os Estados e Municípios não criarem seu próprio regime de licitações para o Sistema do Simples Nacional, deverão ser aplicadas as normas mais favorável a tais empresas previstas em legislação federal, conforme Art. 47 da LC 123/06. Esta determinação legal atende as possíveis situações de omissões ou delongas dos demais membros federados de viabilizar tais acessos, caso não exerçam a competência concorrente, que lhes é garantida. Nestes casos, destaque-se: a regra de contratação exclusiva de microempresas e empresas de pequeno porte cujo valor contratual seja de até $\mathrm{R} \$ 80.000,00$, para cada item de contratação, segundo o Art. 48, I, da LC 123/06; e, na necessidade de contratação de obras e serviços pode-se exigir dos licitantes a subcontratação de microempresa ou empresa de pequeno porte.

Por meio das principais regras promocionais acima indicadas há reais possibilidades de vantagem competitiva em face dos demais licitantes. Logo, a proposta formulada pela pequena empresa terá condições de apresentar valor mais reduzido, possibilitando êxito na licitação. (JUSTEN FILHO, 2007, p. 145).

\section{A LEI COMPLEMENTAR 123/06 E A GESTÃO FEDERATIVA DO SISTEMA}

Importante inovação foi a criação de um sistema federativo para a gestão do Simples Nacional. Nos termos do Art. $2^{\circ}$, da LC 123/06, a estrutura administrativa é composta dos seguintes órgãos: Comitê Gestor do Simples Nacional (CGSN), Fórum Permanente (FP) e Comitê para Gestão da Rede Nacional para Simplificação do Registro e da Legalização de Empresas e Negócios (CGSIM).

O Comitê Gestor do Simples Nacional, vinculado ao Ministério da Fazenda, é composto por representantes da União, dos Estados, do Distrito 
Federal e dos Municípios e tem por finalidade gerir e normatizar aspectos tributários do Sistema. Será presidido e coordenado por representante da União. As normas regulamentadoras editadas por este órgão são introduzidas por ato administrativo Resolução. Ao CGSN compete produzir normas infralegais e estas têm o nível hierárquico de normas gerais administrativas. Esta afirmação considera que: i) as matérias que são de competência deste Comitê objetivam uniformizar o tratamento tributário referente, por exemplo: regulamentar quanto a opção, exclusão, tributação, fiscalização, arrecadação, cobrança, dívida ativa, forma, periodicidade e o prazo relativamente aos tributos apurados na forma do Simples Nacional; ainda, ii) os destinatários imediatos de tais normas são os membros federados União, Estado, Distrito Federal e Municípios limitando ou excluindo no âmbito das competências relativos aos tributos que compõem a arrecadação unificada prevista no Art. $1^{\circ}$, I, da LC 123/06. Este novo sistema está conforme a condição de normas gerais que regulamentam de modo inaugural todo o Sistema Simples por meio de Lei Complementar. Ou seja, é a garantia jurídica, diante das peculiaridades federativas, para harmonizar a convivência normativa das diferentes esferas federativas e das políticas necessárias para alcançar os objetivos constitucionais de inclusão econômica.

O Fórum Permanente das Micro e Pequenas Empresas constitui um espaço de debates e de conjugação de esforços entre os governos federal, estaduais, distrito federal e municípios e fóruns estaduais das microempresas e empresas de pequeno porte e entidades de apoio e de representação nacional do segmento. Reúne, portanto, os interesses dos envolvidos diretamente com o Sistema Simples Nacional. Este órgão, sob presidência e coordenação da Secretaria da Micro e Pequena Empresa da Presidência da República, tem a importante finalidade, nos termos do Art. $2^{\circ}, \S 5^{\circ}$, de "orientar e assessorar a formulação e coordenação da política nacional de desenvolvimento das microempresas e empresas de pequeno porte, bem como acompanhar e avaliar a sua implantação" (BRASIL, 2006). Organizado em Comités Temáticos para construir e avaliar ações em prol da Desoneração e Desburocratização, fomentar o Comércio Exterior, Tecnologia e Inovação, Investimento e Financiamento, Informação e Capacitação, e Compras Governamentais.

O Comitê para Gestão da Rede Nacional para Simplificação do Registro e da Legalização de Empresas e Negócios - CGSIM, vinculado à Secretaria da Micro e Pequena Empresa da Presidência da República, composto por representantes da União, dos Estados e do Distrito Federal, dos Municípios e 
demais órgãos de apoio e de registro empresarial, tais quais: Associação Nacional de Presidentes das Juntas Comerciais; Diretor do Departamento Nacional do Registro do Comércio; Representante do Fórum Permanente. A competência consiste, essencialmente, nos termos da Resolução CGSIM n ${ }^{\circ} 1 / 09$, em seu Art. $4^{\circ}$

regulamentar a inscrição, cadastro, abertura, alvará, arquivamento, licenças, permissão, autorização, registros e demais itens relativos à abertura, legalização e funcionamento de empresários e de pessoas jurídicas de qualquer porte, atividade econômica ou composição societária (BRASIL, 2009).

$\mathrm{Na}$ forma da lei as normas produzidas por este órgão contribuirão para simplificar deveres administrativos nos termos do Art. 179 da CF/88.

\section{AVALIAÇÃO DOS AVANÇOS DO SISTEMA DA MPE SOBRE CRESCIMENTO DO SETOR E GERAÇÃO DE EMPREGOS}

Destacada a importância das possibilidades jurídicas de inclusão econômica é oportuno apresentar resultados dessas políticas e avaliar a contribuição para a inclusão social e a geração de empregos.

Embora existam diversas pesquisas relacionadas ao tema, o presente estudo adotou a publicação Participação das Micro e Pequenas Empresas na Economia Brasileira, de autoria do SEBRAE (SERVIÇO BRASILEIRO DE APOIO ÀS MICRO E PEQUENAS EMPRESAS, 2014), por sua atualidade e por ser um órgão cuja finalidade é promover a competitividade, a capacitação para o desenvolvimento das microempresas e empresas de pequeno porte e gerar dados confiáveis.

Os resultados consolidados na atividade de serviços, entre os anos de 2009 e 2011, geraram as informações representadas nas Tabelas abaixo, que estão organizadas segundo o porte das empresas.

\subsection{Atividade Econômica - Serviços}

$\mathrm{Na}$ Tabela 1, a seguir, constata-se a forte presença das Micro e das Pequenas Empresas que, juntas, representam, na média do período, 98\% de todas as empresas do setor de serviços e geram cerca de $44 \%$ de todo o emprego formal do setor. 
Tabela 1 - Setor de serviços - variáveis 2009 a 2011

\begin{tabular}{|c|c|c|c|c|c|c|}
\hline \multicolumn{7}{|c|}{ SETOR DE SERVIÇOS } \\
\hline \multicolumn{7}{|c|}{ Número de Empresas } \\
\hline Ano & $\begin{array}{l}\text { Micro } \\
\text { Empresas }\end{array}$ & $\begin{array}{l}\text { Pequenas } \\
\text { Empresas }\end{array}$ & $\begin{array}{l}\text { Micro e } \\
\text { Pequenas }\end{array}$ & $\begin{array}{l}\text { Médias } \\
\text { Empresas }\end{array}$ & $\begin{array}{l}\text { Grandes } \\
\text { Empresas }\end{array}$ & Total \\
\hline 2009 & $86,3 \%$ & $11,8 \%$ & $98,1 \%$ & $1,0 \%$ & $0,9 \%$ & $100 \%$ \\
\hline 2010 & $85,9 \%$ & $12,2 \%$ & $98,1 \%$ & $1,0 \%$ & $0,9 \%$ & $100 \%$ \\
\hline 2011 & $87,0 \%$ & $11,2 \%$ & $98,2 \%$ & $0,9 \%$ & $0,9 \%$ & $100 \%$ \\
\hline \multicolumn{7}{|c|}{ Pessoal Ocupado } \\
\hline Ano & $\begin{array}{l}\text { Micro } \\
\text { Empresas }\end{array}$ & $\begin{array}{l}\text { Pequenas } \\
\text { Empresas }\end{array}$ & $\begin{array}{l}\text { Micro e } \\
\text { Pequenas }\end{array}$ & $\begin{array}{l}\text { Médias } \\
\text { Empresas }\end{array}$ & $\begin{array}{l}\text { Grandes } \\
\text { Empresas }\end{array}$ & Total \\
\hline 2009 & $22,1 \%$ & $21,2 \%$ & $43,3 \%$ & $6,8 \%$ & $49,9 \%$ & $100 \%$ \\
\hline 2010 & $21,2 \%$ & $22,0 \%$ & $43,2 \%$ & $6,7 \%$ & $50,1 \%$ & $100 \%$ \\
\hline 2011 & $23,1 \%$ & $21,0 \%$ & $44,1 \%$ & $6,6 \%$ & $49,4 \%$ & $100 \%$ \\
\hline
\end{tabular}

Fonte: Serviço Brasileiro de Apoio às Micro e Pequenas Empresas (2014).

\subsection{Atividade Econômica - Comércio}

No comércio, a participação das Micro e Pequenas Empresas é ainda mais expressivo, cerca de $99 \%$ na média do período, do total das empresas classificadas na atividade comércio. No que tange às informações de emprego, constata-se que, cerca de $70 \%$ do pessoal ocupado está alocado nas Micro e Pequenas Empresas.

Tabela 2 - Setor de comércio - variáveis 2009 a 2011

\begin{tabular}{lllllll}
\hline \multicolumn{2}{l}{ SETOR DE COMÉRCIO } & & & & \\
\hline \multicolumn{2}{l}{ Número de Empresas } \\
\hline Ano & Micro & Pequenas & Micro e & Médias & Grandes & \multirow{2}{*}{ Total } \\
\hline 2009 & $89,6 \%$ & $9,7 \%$ & $99,2 \%$ & $0,5 \%$ & $0,3 \%$ & $100 \%$ \\
2010 & $89,2 \%$ & $9,9 \%$ & $99,2 \%$ & $0,5 \%$ & $0,3 \%$ & $100 \%$ \\
2011 & $89,3 \%$ & $9,9 \%$ & $92,2 \%$ & $0,5 \%$ & $0,3 \%$ & $100 \%$ \\
\hline Pessoal Ocupado & & & & & \\
\hline \multirow{2}{*}{ Ano } & Micro & Pequenas & Micro e & Médias & Grandes & \multirow{2}{*}{ Total } \\
\hline 2009 & Empresas & Empresas & Pequenas & Empresas & Empresas & \\
2010 & $41,2 \%$ & $28,3 \%$ & $69,5 \%$ & $5,7 \%$ & $24,8 \%$ & $100 \%$ \\
2011 & $39,8 \%$ & $28,3 \%$ & $68,2 \%$ & $5,8 \%$ & $26,0 \%$ & $100 \%$ \\
\hline
\end{tabular}

Fonte: Serviço Brasileiro de Apoio às Micro e Pequenas Empresas (2014). 


\subsection{Atividade Econômica - Indústria}

Por fim, no setor industrial, embora as Médias e Grandes Empresas ainda concentrem a maioria dos funcionários empregados, é salutar o crescimento das Micro e Pequenas Empresas que atuam no setor industrial, tanto é que cerca de $95 \%$ das empresas desse setor são de pequeno porte.

Tabela 3 - Setor da indústria - variáveis 2009 a 2011

\begin{tabular}{|c|c|c|c|c|c|c|}
\hline \multicolumn{7}{|c|}{ SETOR DA INDÚSTRIA } \\
\hline \multicolumn{7}{|c|}{ Número de Empresas } \\
\hline Ano & $\begin{array}{l}\text { Micro } \\
\text { Empresas }\end{array}$ & $\begin{array}{l}\text { Pequenas } \\
\text { Empresas }\end{array}$ & $\begin{array}{l}\text { Micro e } \\
\text { Pequenas }\end{array}$ & $\begin{array}{l}\text { Médias } \\
\text { Empresas }\end{array}$ & $\begin{array}{l}\text { Grandes } \\
\text { Empresas }\end{array}$ & Total \\
\hline 2009 & $79,3 \%$ & $16,2 \%$ & $95,5 \%$ & $3,5 \%$ & $1,0 \%$ & $100 \%$ \\
\hline 2010 & $78,7 \%$ & $16,7 \%$ & $95,4 \%$ & $3,6 \%$ & $1,0 \%$ & $100 \%$ \\
\hline 2011 & $79,5 \%$ & $16,0 \%$ & $95,5 \%$ & $3,5 \%$ & $1,0 \%$ & $100 \%$ \\
\hline \multicolumn{7}{|c|}{ Pessoal Ocupado } \\
\hline Ano & $\begin{array}{l}\text { Micro } \\
\text { Empresas }\end{array}$ & $\begin{array}{l}\text { Pequenas } \\
\text { Empresas }\end{array}$ & $\begin{array}{l}\text { Micro e } \\
\text { Pequenas }\end{array}$ & $\begin{array}{l}\text { Médias } \\
\text { Empresas }\end{array}$ & $\begin{array}{l}\text { Grandes } \\
\text { Empresas }\end{array}$ & Total \\
\hline 2009 & $17,9 \%$ & $24,7 \%$ & $42,5 \%$ & $25,1 \%$ & $32,4 \%$ & $100 \%$ \\
\hline 2010 & $17,2 \%$ & $24,6 \%$ & $41,8 \%$ & $25,2 \%$ & $33,1 \%$ & $100 \%$ \\
\hline 2011 & $17,4 \%$ & $24,2 \%$ & $41,5 \%$ & $24,9 \%$ & $33,6 \%$ & $100 \%$ \\
\hline
\end{tabular}

Fonte: serviço Brasılııro de Apoı as Ivııcro e requenas Empresas (LU14).

Considerando os dados obtidos no estudo em destaque é possível afirmar a relevância das Micro e Pequenas Empresas no panorama econômico nacional. Limongi França (2011, p. 35) afirma que o empreendedorismo é a chama que leva o homem ao novo, ao desafio, ao novo negócio. Para o autor, o tratamento diferenciado se justifica, pois:

Favorece o Estado as MPEs para que tenham a oportunidade de se desenvolverem em meio a uma concorrência cada vez mais cruel, na medida em que as empresas de maior porte não darão chance alguma às menores, a não ser que, depois de análises e verificações sobre retornos de investimentos, verifiquem ser mais vantajoso a elas a convivência com as pequenas ou mesmo a parceria de negócios com elas. (FRANÇA, 2011, p. 35).

O marco legal da LC 123/06, para inclusão e permanência, positiva a regra constitucional do direito a tratamento especial e favorecido daqueles 
que estão na informalidade ou que se dispõe a desenvolver atividades em mercado fortemente concorrencial. O apoio institucional viabiliza oportunidades e não deve ser avaliado no nível de privilégios jurídicos. Tratase da possibilidade de vivenciar as conquistas da igualdade material no âmbito econômico.

Apontadas intervenções dos Poderes Legislativo e Executivo, oportuno, por fim, também tratar da salutar participação interpretativa do Judiciário na busca pela redução da informalidade. Neste sentido destaquese a ação direta de inconstitucionalidade ADI n ${ }^{\circ}$ 4033, proposta pela Confederação Nacional do Comércio e julgada no STF onde foi analisada a isenção concedida às microempresas e empresas de pequeno porte com relação à contribuição sindical patronal.

Isenção concedida às microempresas e empresas de pequeno porte. Simples Nacional ('Supersimples'). LC 123/06, Art. 13, § $3^{\circ}$. (...) O fomento da micro e da pequena empresa foi elevado à condição de princípio constitucional, de modo a orientar todos os entes federados a conferir tratamento favorecido aos empreendedores que contam com menos recursos para fazer frente à concorrência. Por tal motivo, a literalidade da complexa legislação tributária deve ceder à interpretação mais adequada e harmônica com a finalidade de assegurar equivalência de condições para as empresas de menor porte. Risco à autonomia sindical afastado, na medida em que o benefício em exame poderá tanto elevar o número de empresas a patamar superior ao da faixa de isenção quanto fomentar a atividade econômica e o consumo para as empresas de médio ou de grande porte, ao incentivar a regularização de empreendimentos (BRASIL, 2011, p. 1817).

A ADI questionava a legalidade do Art. $13, \S 3^{\circ}$ da LC 123/06, que isentou as micro e pequenas empresas do pagamento de contribuição sindical. A Confederação Nacional do Comércio sustentou que a isenção concedida violou a reserva de lei específica para concessão de benefícios fiscais de que trata o Art. $150, \S 6^{\circ}$ da $\mathrm{CF} / 88$. O argumento foi de que a LC 123/06 não versa exclusivamente sobre a isenção e que houve violação da reserva de lei complementar para dispor sobre o tratamento diferenciado de que trata o Art. 146, III, d, da CF/88. Acrescentou que a isenção traz grave risco à manutenção do sindicalismo patronal, eis que os beneficiários pela LC 123/06, representam a quase totalidade das empresas de comércio 
do país. Porém, o acórdão reconheceu que a isenção não viola o Art. $150, \S$ $6^{\mathrm{o}}$ da $\mathrm{CF} / 88$, pois a contribuição sindical é tributo de competência da União e que a lei não se ocultou ao dispor sobre a exoneração tributária. A isenção também não viola o Art. 146, III, d, da CF/88, pois a lista de tributos prevista no texto legal que define o campo de reserva da lei complementar é exemplificativa e não taxativa.

Destaque-se a afirmação do STF no sentido de que a decisão em favor da isenção prevista na LC 123/06, está conforme a regra constitucional prevista no Art. 170, IX. Nesta condição, se impõe no nível de diretriz interpretativa do ordenamento jurídico de forma sistemática. A isenção trazida por meio da Lei complementar é norma federal e poderia ter sido introduzida por meio de Lei Ordinária. Portanto, foi introduzida por meio de processo legislativo que exige quórum qualificado. Tal tratamento está conforme o Art. 179 da CF/88 e os demais princípios que compõem o regime jurídico econômico constitucional, conforme argumento de que é válido "conferir tratamento favorecido aos empreendedores que contam com menos recursos para fazer frente à concorrência”.

\section{CONSIDERAÇÕES FINAIS}

A presente pesquisa reúne fundamentos teóricos de Hernando Soto (2001) a partir do livro Mistério Capital. O desafio do estudo do autor parte da constatação de que o sistema econômico capitalista falha nos países desenvolvidos e ex-comunistas, mas, avança nos países em desenvolvimento. Entre as importantes análises e conclusões que apresenta, destaca-se a indicação que faz sobre o potencial dos ativos dos cidadãos para produzir capital e assim alavancar produção, novos serviços, renda, emprego. Para tanto é fundamental o acesso ao direito de propriedade, pois ela é a base da construção do capitalismo. Por meio deste caminho os ativos que denomina de "capital morto", e que estão no campo econômico da informalidade, poderão ser transformados em capital (bens que geram outros bens) e se integrar à economia formal. Assim, passam a fazer parte da redoma de vidro de Braudel, (referindo-se ao historiador Fernand Braudel), onde estão os poucos que usufruem dos efeitos jurídicos da propriedade privada. Estes estão no campo da legalidade e dos acessos que lhes é oferecido por meio de políticas públicas. 
A partir destes estudos a pesquisa foca o Sistema Brasileiro do Simples Nacional criado por meio da Lei Complementar 123/06 e já aperfeiçoado por várias outras leis, para indicar que a intervenção do Estado para enfrentar o desafio da inclusão econômica, a que se refere Hernando Soto, está em bom caminho. Esta iniciativa legal tem por competência as normas do Art. 170 , IX e 179 da $\mathrm{CF} / 88$, por meio da regulação normativa, fiscalização e fomentos previstas no Art. 174 da CF/88.

O critério para inclusão neste sistema é a receita bruta anual com restrições para algumas atividades econômicas. Entre os obstáculos para a formalização que a Lei Complementar possibilita enfrentar está: a simplificação em âmbito de obrigações administrativas para obter licenças e registros; desobrigações quanto a deveres de natureza trabalhista; garantia de implementar políticas para acesso a créditos público; incentivos e assessoria para inovações; preferências para participar de negócios públicos, inclusive, prestigiando a economia local e regional; fiscalização de cunho orientativo, exigindo pelo menos duas visitas antes de autuar; e, a criação de um regime único, de menor carga tributária e simples, para a arrecadação de tributos de competência da União, Estado, Distrito Federal e Municípios.

Deve-se destacar a importância desta Lei Complementar uma vez que este Sistema Simples é de âmbito nacional (normas gerais), portanto, as normas que ela introduziu têm por destinatários imediatos todos os membros da federação. Por meio desta categoria de normas promove-se unidade, uniformidade e coordenação centralizada. Tal opção gera um sistema harmônico e estável, uma vez que qualquer alteração envolve, necessariamente, um maior quórum legislativo e a necessidade de diálogo com número maior de membros.

Para gerir o Simples Nacional, nos termos do Art. $2^{\circ}$, foram criados os seguintes órgãos: Comitê Gestor do Simples Nacional (CGSN), Fórum Permanente (FP) e Comitê para Gestão da Rede Nacional para Simplificação do Registro e da Legalização de Empresas e Negócios (CGSIM). O primeiro comitê é formado por representantes dos membros da federação, União, Estados, Distrito Federal e Municípios e tem competência para produzir normas infralegais. Elas são introduzidas por meio ato administrativo Resolução. Tais normas tem nível de norma infralegal geral. Este nível normativo é uma nova experiência jurídica e pode ser equiparada ao regime da competência legislativa concorrente, prevista no Art. 24 da CF/88. 
O Fórum Permanente é o órgão que permite o exercício de avaliar a eficiência do Sistema Simples. Dele fazem parte, além dos membros federativos os representantes das entidades vinculadas ao setor do Simples Nacional. Aproxima os envolvidos diretamente para discussões, críticas e encaminhamentos de políticas públicas que tornem o Sistema mais eficiente. Este Fórum, portanto, possibilita a prática de democracia participativa. As consequências de tal ambiente são a legitimidade e fortalecimento do pacto que deve existir entre as esferas públicas e privadas.

O mais recente Comitê é para Gestão da Rede Nacional para Simplificação do Registro e da Legalização de Empresas e Negócios (CGSIM), cujos participantes além dos membros federativos são representantes das Juntas Comerciais, do Departamento Nacional do Registro do Comércio e Representante do Fórum Permanente. Esta composição permite, efetivamente, buscar soluções para a crítica apontado por Hernando Soto quanto a burocracia excessiva e complicada que afasta os pequenos empresários, muitas vezes inviabilizando o acesso ao mercado formal.

Considerando os dados colhidos defende-se a importância da microempresário individual, microempresa e empresa de pequeno porte, confirmando a relevância destes empresários, apontada por Hernando Soto. Assim, defende-se que o Sistema Brasileiro do Simples Nacional está apto a enfrentar as dificuldades de inclusão e permanência econômica, em um pais em desenvolvimento.

Pode-se afirmar que há caminhos jurídicos acessíveis para a transformação em capital dos ativos que estão na informalidade. É necessário reconhecer a força deste "capital morto" e buscar confiança deste empreendedores por meio de oportunidades. Percorrendo este caminho vivencia-se as externalidades positivas do capitalismo, iniciando-se com a valorização dos potenciais humanos, segue-se com estímulos à livre iniciativa que fortalece um ambiente concorrencial por meio da igualdade material.

\section{REFERENCIAS}

ALMEIDA, Amador Paes (Org.). Comentários ao estatuto da microempresa e da empresa de pequeno porte: lei complementar $n$. 123/06. São Paulo: Saraiva, 2009. 


\section{BRASIL. Constituição da República Federativa do Brasil de 1988.}

Disponível em: $<$ http://www.planalto.gov.br/ccivil_03/constituicao/

ConstituicaoCompilado.htm>. acesso em: 5 out. 2015.

. Decreto-Lei $n^{0} \mathbf{1 . 7 8 0}$, de 14 de abril de 1980. Concede isenção do imposto sobre a renda às empresas de pequeno porte $\mathrm{e}$ dispensa obrigações acessórias. Disponível em: $<$ http:// www.planalto.gov.br/ccivil_03/decreto-lei/1965-1988/Del1780.htm>. Acesso em: 4 out. 2015.

. Decreto $\mathbf{n}^{0} \mathbf{6 . 8 8 4}$, de 25 de junho de2009. Institui o Comitê para Gestão da Rede Nacional para a Simplificação do Registro e da Legalização de Empresas e Negócios - CGSIM. Disponível em: <http:// www.planalto.gov.br/ccivil_03/Ato2007-2010/2009/Decreto/ D6884.htm>. Acesso em: 5 out. 2015.

\section{Lei Complementar $n^{0}$ 123, de 14 de dezembro de 2006.} Institui o Estatuto Nacional da Microempresa e da Empresa de Pequeno Porte; altera dispositivos das Leis no 8.212 e 8.213, ambas de 24 de julho de 1991, da Consolidação das Leis do Trabalho - CLT, aprovada pelo Decreto-Lei no 5.452, de 1 o de maio de 1943, da Lei no 10.189 , de 14 de fevereiro de 2001, da Lei Complementar no 63, de 11 de janeiro de 1990; e revoga as Leis no 9.317, de 5 de dezembro de 1996, e 9.841, de 5 de outubro de 1999. Disponível em: <http://www.planalto.gov.br/ccivil_03/ leis/LCP/Lcp123.htm>. Acesso em: 4 out. 2015.

. Lei $\mathbf{n}^{0}$ 6.939, de 9 de setembro de 1981. Institui o regime sumário de registro e arquivamento no Registro do Comércio e dá outras providências. Disponível em: <http://www.planalto.gov.br/ccivil_03/leis/ 1980-1988/L6939.htm>. Acesso em: 5 out. 2015.

\section{Lei Complementar $n^{0}$ 48, de 10 de dezembro de 1984a.}

Estabelece normas integrantes do Estatuto da Microempresa, relativas a isenção do imposto sobre Circulação de Mercadorias - ICM e do Imposto sobre Serviços - ISS. Disponível em: <http://www.planalto.gov.br/ ccivil_03/leis/LCP/Lcp48.htm>. Acesso em: 4 out. 2015. 
. Lei $n^{0} 7.256$, de 27 de novembro de 1984b. Estabelece

Normas Integrantes do Estatuto da Microempresa, Relativas ao

Tratamento Diferenciado, Simplificado e Favorecido, nos Campos Administrativo, Tributário, Previdenciário, Trabalhista, Creditício e de Desenvolvimento Empresarial. Disponível em: $<$ http:// www.planalto.gov.br/ccivil_03/Leis/L7256.htm>. Acesso em: 5 out. 2015.

. Superior Tribunal de Justiça. REsp 1257391/RS. Relatora Ministra Eliana Calmon, Segunda Turma, Brasilia, Julgado em 18/06/2013. Diário da Justiça, Brasília, 26 jun. 2013.

. Supremo Tribunal Federal. A constituição e o supremo. 4. ed. Brasília: Secretaria de Documentação, 2011.

DERANI, Cristiane. Direito ambiental econômico. São Paulo: Saraiva, 2008.

FRANÇA, Antônio de S. Limongi. As pequenas e as microempresas no direito brasileiro. Curitiba: Juruá, 2011.

GARCIA, José Carlos Cal. Linhas mestras da constituição de 1988. São Paulo, Saraiva, 1989.

JUSTEN FILHO, Marçal. O estatuto da microempresa e as licitações públicas. 2. ed. São Paulo: Dialética, 2007.

MARTINS, Ives Gandra Da Silva. A Constituição Federal e as empresas de pequeno porte - inteligência dos artigos 170 inciso ix e 179 da lei suprema - parecer. São Paulo: Universidade Mackenzie, 1992.

MONTAÑO, Carlos. Microempresa na era da globalização. São Paulo: Cortez, 1999.

RIBEIRO, Carlos Reinaldo Mendes. O estatuto (contra a) microempresa. São Paulo: Alfa-ômega, 1984. 
SÁ, Antônio Lopes. Tudo sobre a microempresa. Belo Horizonte: Tecnoprint, 1985.

SACHS, Ignacy. Inclusão social pelo trabalho: desenvolvimento humano, trabalho decente e o futuro dos empreendedores de pequeno porte no Brasil. Rio de Janeiro: Garamond, 2003.

SANTOS, José Anacleto Abduch. As licitações e o estatuto da microempresa. Revista JML de Licitações e Contratos, Curitiba, v. 1, n. 3, p. 3-20, jun., 2007.

SERVIÇO BRASILEIRO DE APOIO ÀS MICRO E PEQUENAS EMPRESAS - SEBRAE. Participação das micro e pequenas empresas na economia brasileira. Brasília: SEBRAE, 2014.

SILVA, Renaldo Limiro; LIMIRO, Alexandre. Manual do supersimples: comentários à lei geral das microempresas e empresas de pequeno porte. Curitiba: Juruá, 2007.

SOTO, Hernando. O mistério do capital. Tradução de Zaida Maldonado. Rio de Janeiro: Record, 2001.

Submetido em 06/10/2015 Aprovado em 18/11/2015

Como citar: MONTEIRO, Philippe Antonio Azedo; KEMPFER, Marlene. A informalidade e a inclusão econômica por meio do estatuto nacional da microempresa. Scientia Iuris, Londrina, v.19, n.2, p.127-153, dez. 2015. DOI: $10.5433 / 2178-8189.2015 \mathrm{v} 19 \mathrm{n} 2 \mathrm{p} 127$. ISSN 2178-8189. 